\title{
A Critical Review of Translation: A Look Forward
}

\author{
Morteza Abdi Saroukhil ${ }^{1}$, Omid Ghalkhani², Ali Hashemi ${ }^{3 *}$ \\ 'Payame Noor University, Qazvin, Iran \\ ${ }^{2}$ Islamic Azad University, Science and Research Branch, Tehran, Iran \\ ${ }^{3}$ Zanjan University, Zanjan, Iran
}

Corresponding author: Ali Hashemi, E-mail: a.kian.hashemi@gmail.com

\begin{tabular}{l} 
ARTICLE INFO \\
\hline Article history \\
Received: May 30, 2017 \\
Accepted: April 25, 2018 \\
Published: April 30, 2018 \\
Volume: $6 \quad$ Issue: 2 \\
\hline
\end{tabular}

Conflicts of interest: None Funding: None

\begin{abstract}
Human beings live in a social world and interaction is at the heart of human society with language being the tool for this interaction and communication. In a world marked by globalization and global communication, there is a deeply-felt need for mutual understanding among people of diverse cultures and languages. In the absence of a common universal language for all, this very need is met by translation. Translation plays a fundamental role in exchanging views and information between languages. Thus, translation coexists with communication and language, and various societies need translation for communication purposes. This article aims at providing a concise background of the translation studies, theories and areas, as well as a discussion on the current issues and future perspectives. Meanwhile, the necessity of teaching translation and integrating it into school program is discussed. It is hoped that the article will familiarize the reader with a comprehensive view of translation and current issues of interest in translation.
\end{abstract}

Key words: Translation, Translation Theories, Translation Types, Translation Future, Teaching Translation

\section{INTRODUCTION}

Translation is unavoidable in today's modern world. The significance of translation arises from its application in various aspects of cultural, commercial, economic, literary, and diplomatic aspects of modern life. As a result of globalization, borders among cultures are vanishing, and consequently, the need for understanding is emerging at the same time. The question here is how this gap is to be filled and this understanding is going to occur in spite of vast variations and diverse discrepancies among cultures. The answer to this question would be translation.

\section{DEFINITIONS OF TRANSLATION}

Translation in the broad sense is used to refer to one of these concepts:

1. the practice of rendering the source text into the target text.

2. a technique for teaching foreign languages. Particularly in the old Grammar Translation method.

3. an academic field comprising other language related disciplines.

Diverse definitions of translation have been proposed. This variation in conceptualizing the essence and nature of translation is due to various scholars' notions in this concern, for each has attempted and approached it in a particular perspective. Nida (1964) has rightly pictured this diversity. These definitions, as Nida observers, are as diverse as those who have discussed the point. This variety stems from discrepancies in the materials, purpose, and the needs of the audience.

To Catford, translation is the replacement of textual material in source language (SL), by equivalent textual material in the target, language (TL) (Catford, 1965). However, this definition is rather wide and vague and needs more clarification. Nida and Taber offer a more detailed and precise definition (1969). The definition of translation, accordingly, is the reproduction of the closest natural equivalent, in terms of meaning and style, of the source language message into the target language. In either case, equivalence plays a key role in these definitions.

Equivalence also is stressed in other views of translation. According to Koller (1979), translation is transposition of a source-language material is into a target-language text. The relationship of the source text and the target text is that of an equivalence.

There are other researchers who have conceptualized translation in similar fad. Newmark (1998), for example, believes that translation is the substitution of the meaning of a text into another language as intended by the author. Newmark's view is also in line with that of Koller, as stated above. 
Meaning and style constitute the basis of the definition by Bell (1991). Translation to Bell, is expressing in the target language of what has been expressed in the source language, preserving semantic and stylistic equivalences.

\section{TRANSLATION AND FOREIGN/SECOND LANGUAGE INSTRUCTION}

Translation constituted a substantial portion of language teaching in the past, and then lost attraction for a while. With the emergence and domination of communicative methodologies, translation was frowned upon and banished from the realm of language teaching. However, later, theorists come to the idea of the profitability of translation and now translation is a quality of communicative learning, albeit with a different attitude. Accordingly, Duff (1989) holds that teachers and learners use translation to learn, rather than learning translation.

\section{TRANSLATION AS PRODUCT AND TRANSLATION AS COMPETENCE}

Until the 1980s, translation theory was mainly concerned with (Lörscher, 1991) with translation as competence and translation as product. The latter is a written text in target-language (TL) that is analyzed by a comparison with the source-language text. This relationship between the SL text and the TL text had been the subject of the various models of equivalence (Koller, 1995). However, these early models of translation were theoretical and of limited practical use.

The theory of translation as competence primarily focused on the knowledge skills, and abilities of the translator. The models of translation were theoretical and speculative rather than empirical, and were based on idealizations rather than on actually occurring data (Toury, 1980).

\section{TYPES OF TRANSLATION}

Translation specialists have hypothesized translation in a number categories each of which seeks to summon the most characteristic feature or an agreed quality. These classifications of translation types are in the forms of dichotomies in binary oppositions.

The earliest type is 'literal' vs 'free' translation. Other types of translation include 'literary' vs 'non-literary', 'semantic' vs 'communicative', 'static' vs 'dynamic'. The 'literal' vs 'free' type of translation concerns the closeness, emphasizing loyalty to the ST (source text). The 'literary' vs 'non-literary' type of translation presupposes the source message to be conveyed in a different form.

\section{Catford's Translation Types}

Catford (1965) classifies translation, into a variety of categories which are presented here:

A) Full vs. Partial translation in terms of the extent of submission of SL text to the process of translation.

B) Total vs. Restricted translation in the sense of the levels of language involved in translation.
C) Rank of Translation which concerns the rank in a grammatical hierarchy to which translation equivalence is established.

\section{Jakobson's Translation Types}

Jakobson (2000) makes distinction among the different ways of, translating, or interpreting, a sign.

1. Intralingual translation (rewording): the interpretation of signs using other signs of the same language.

2. Interlingual translation (translation proper): the interpretation of signs using some other language.

3. Intersemiotic translation (transmutation): the interpretation of signs using signs of nonverbal sign system.

In Jakobson's classification, the intralingual type is embodied in the use of synonyms in the same language (paraphrasing). The second type is the replacing of words or phrases in SL by the best equivalents in the target language. And finally, the third concerns the use of signs for the purpose of communication such as sign language and traffic signals (Shuttleworth \& Cowie, 2007).

The reason for the wide differences in the views and theories concerning translation is that interlingual communication is both old and complex. To Richards (1953), interlingual communication is amazingly complex "probably the most complex type of event yet produced in the evolution of the cosmos". Interestingly, albeit extremely complex, it is also completely natural (Harris \& Sherwood, 1978).

\section{HISTORY OF TRANSLATION}

\section{Prescientific or Pre-linguistic Era}

\section{The ancient period}

With the evolution of cultures and societies, translation, too, took shape and emerged based on the needs of communities. Different societies wanted to maintain their memories in the form of epigraphs as well as inscriptions which are now being decoded in numerous languages as translations.

In the past, all theoretical approaches developed for translation focused on what a translator must or must not do. They were primarily concerned with the closeness, in terms of meaning and form, of target text to the source text; the translator has to do any effort to reproduce the text as carefully and closely as possible. The ancient time has witnessed the general debate over the two trends in translation:

- the 'word for word' or 'literal' translation

- the 'sense for sense' or 'free' translation

The two paramount figures of this period, namely Horace and Cicero, distinguish between sense for sense translation and word for word translation. They argue in favor of free or sense for sense translation. They believe in the superiority of this approach and they do it in practice. As Bassnett states the basic value of enriching the native language by means of translation lead to an emphasis placed on the aesthetic principles of the TL product rather than the slavish concept of 'fidelity' (Bassnett, 1980). Cicero holds that in rendering translation as literal, the product will be uncouth, and if it is, otherwise, necessary, then something in the order or wording should be changed (in Nida 1964). Likewise, Horace reiterating Cicero's view, advises the 
translator not to worry about rendering literal, faithful translation, rather use sense for sense translation (in Robinson 1997).

\section{The middle ages}

As Steiner rightly states, up to the second half of the twentieth century, translation theory was concerned with a 'sterile' argument over the notions of 'literal', 'free' and 'faithful' translation (Steiner, 1998). The difference between 'wordfor-word' and 'sense-for-sense' translation dates back to Cicero and St. Jerome and forms the basis of many discussions on translation.

The disregard for word-for-word translation by Cicero and Horace, for the sake of creating an artistically creative text, deeply impacted the subsequent centuries (Munday, 2001). St Jerome, for example, revised the former Latin translations of the New Testament. He justifies his own Latin revision of the Christian Bible resorting to Cicero.

According to Munday (2001), Jerome's justification favored 'free'(sense-for-sense) translation and prohibited the word-forword approach as cloaking the sense of the original text.

\section{Renaissance}

Renaissance covers the Western Cultural Movement's history and fills the gap between Middle Ages and Modern era. This period in time marked the rebirth of humanism, and the revival of cultural accomplishments (Wikipedia). During Renaissance, translations were largely from Greek origin. Renaissance stirred various translations of scientific and religious texts.

The first person who formally set the basic rules of translation studies is the French Etienne Dolet, (Bijay, 2005). Dolet devised major principles for translation which are still in common agreement. According to Dolet:

- The translator must fully understand the sense and meaning of the original author

- The translator should have good knowledge of both SL and TL.

- The translator should avoid word-for-word rendering.

- The translator should use forms of speech in common use.

- The translator should choose words appropriately to produce the correct tone.

George Chapman, the translator of Homer, in line with Dolet, highlighted on the spirit of the source text rather than word for word translation. Qabil states Chapman's meaning well. According to Chapman, translator is to bring about a "transmigration" of the original text on both the technical and metaphysical level, as a skill equal with duties and responsibilities both to the author and to the audience (Qabil, 2005).

Abraham Cowley, too, marches in the same path as the above mentioned theorists. He holds, according to Firdaus, that he translated not so much focusing precisely on what the original author said but more on his way and manner of speaking. Thus, Cowley believes in free translation (Firdaus, 2012).

\section{The new ages}

Translation, at that time, was limited to free verse renderings of Greek and Latin classics into English. Translators attacked loss of beauty in translation and insisted on maintaining the spirit and originality of the source text. The idea of slavish translation was repressed as leading to suppressing the originality and spirit of the source text.

The free approach to translation adopted by translators, mostly poet translators, induced a reaction, from John Dryden. Dryden's description of the process of translation had profound impact on the later translation theory and practice. Dryden (1992) divides translation to three classes:

1. Metaphrase: 'word by word' translation corresponding to literal translation;

2. Paraphrase: 'translation with latitude' the translator keeps the content and message, but does not adhere so strictly to the form as to his sense'; (corresponding to sense-for-sense translation)

3. Imitation: 'forsaking' both form and meaning; (corresponding to free translation).

Dryden and other writers at the time were very prescriptive, tending to set out standards for correction and successful translation. Dolet was one of the other prescriptive writers of the time (Dolet, 1997). Dolet prescribed five principles:

1. The translator needs to understand the form and meaning, yet he is feel free to clarify points

2. He needs to have a thorough understanding of both source language and target language.

3. He should refrain from word-for-word translation.

4. He should avoid uncommon and archaic forms.

5. He should have an eye on aestheticism.

Tytler's notion of translation, too, is in line with Cicero and Horace. To Tytler (in Bell, 1991), translation should transfer the quality and worth of the source text into target text. Accordingly, translation is good to the point that it provides a picture of the ideas, and faithfully represent the author's voice in the original text.

Schleiermacher is noted for an approach to interpretation based not on absolute truth but on the individual's inner feeling and understanding (Munday, 2001/2008). Schleiermacher (2004) makes distinction between two types of translators:

1. The commercial texts translator

2. The scholarly and artistic texts translator

Schleiermacher abandons the notions of word-for-word and sense-for-sense translation, and decides that the translator should either place more stress on the writer and push the reader toward him, or bring the reader to the forefront and push the writer toward him.

\section{The modern ages}

This era witnessed a discussion on the position of the source text and the form of the target language. Two eminent scholars of this time are Francis Newman and Matthew Arnold. The controversial issue between these two occurred over the translation of Homer (Venuti 1995; Robinson 1997). Matthew Arnold gives precedence to the source text with complete commitment.

Newman stressed on the preserving of the foreignness of original text by a deliberate use of unusual and antiquated vocabulary in translation. Matthew Arnold vehemently attacked this approach to translation and instead favored a clear translation method. 


\section{Linguistic Theories}

Linguistic theories considered translation as a part of linguistics, and not as an independent discipline. It was late in the $20^{\text {th }}$ century that Translation gained prominence and considered as an independent discipline. The first scholar to coin and use the term Translation Studies was James Holmes. Holmes believed that the development of a comprehensive translation theory was the primary goal of Translation Studies (Gentzler, 1993).

'Information Theory', the basis of linguistic communication theory (Gentzler, 1993), considers language as a 'code.' In interaction, speakers use an encoding process to convey what they wish, and the listeners use a decoding process to reconstruct meaning. However, in translation the sender and the receiver use different codes; therefore, it necessitates translation to assist understanding by recoding the message from the sender into the receiver code.

Linguistic theories encompass a range of different theories on the nature of language and translation. However, their basic feature is focus on the linguistic system. According to Snell- Hornby (1988), what characterizes these theories is preoccupation with equivalence. Based on this theory, language and translation are considered as separate from communicative context and function.

Roman Jakobson classified translation into three kinds: intralingual, interlingual and inter- semiotic. Interlingual translation is translation between two languages. Jakobson (2004) considers equivalence and linguistic meaning as the main concerns of Interlingual translation.

In Jakobson's view, interlingual translation is replacing messages in the source language for messages in the target language. The translator conveys a message from one language into another language. Therefore, translation implicates two equivalent messages in two different languages.

Eugene Nida developed his theory based on practical experience. He elaborates on different approaches to meaning. He considers meaning in terms of linguistic, referential (denotative or dictionary), and emotive (connotative) sense. Nida abandons old terms of free and literal translation and focuses on dynamic equivalence and formal equivalence.

Formal equivalence emphasizes the form and content of the message, and a precise correspondence in the source language and the target language (Nida, 1964). By dynamic equivalence, he means "naturalness". The message must conform to the linguistic and cultural needs of the target language and. Nida defines dynamic equivalence as 'the closest natural equivalent to the source-language message' (Nida,1964; Nida \& Taber, 1969).

For Nida (1964), translation requires attention to:

1. Making sense;

2. Conveying the spirit and manner of the original;

3. Having a natural and easy form of expression;

4. Producing a similar response.

Peter Newmark is a significant figure in translation studies. He discards Nida's receptor-oriented approach to translation, and instead focuses on communicative and semantic translation (Newmark, 1981).

According to Newmark, semantic translation tries to transmit, as closely as possible, the exact contextual meaning of the source text. Communicative translation, on the other hand, strives to produce, as closely as possible, the effect the source text has on the readers of the original (Newmark, 1981).

Semantic translation is loyal to the author, and inferior to source text, communicative translation feels the opposite: target text is better than source text and it is less loyal to source language. Semantic translation is mostly for serious literature and autobiography, but communicative translation is used for the vast majority of texts. While communicative translation transfers foreign features into the target culture, Semantic translation remains within the realm of source culture.

Werner Koller focuses on correspondence and equivalence. Correspondence is the corresponding of structures and sentences in the SL and TL. Equivalence describes the hierarchy of utterances and texts in SL and TL according to equivalence criteria (Koller, 1979).

Equivalence, in Koller's view, is of different types (Koller, 1979):

1. Denotative equivalence concerns the extra-linguistic content.

2. Connotative equivalence concerns the lexical elements.

3. Text-normative equivalence concerns the different classes of texts.

4. Pragmatic equivalence, or 'communicative equivalence', is concerned with the receiver of the message.

5. Formal equivalence, concerns the aesthetic or stylistic features of the ST.

Vinay and Darbelnet (1995) paid attention to translation strategies. They divided them to direct translation and oblique translation. Their classification reminds us of the older literal and free techniques. According to these researchers (1995), direct translation covers three procedures:

1. Borrowing: SL is directly transferred to the TL.

2. Calque: the SL expression is literally transferred and translated to into the TL

3. Literal translation or 'word-for-word' translation.

However, in case literal translation is impossible, oblique translation is used. This strategy encompasses four procedures:

1. Transposition: changing parts of speech while preserving the sense. This procedure is further divided into obligatory and optional.

2. Modulation: changing the semantics and point of view, which in turn could be further divided into obligatory and optional.

3. Equivalence: this applies to cases in which the same situation could be described by various stylistic or structural means, especially in translating idioms and proverbs.

4. Adaptation: this applies to cases in which the target culture lacks features existing in the source language.

Catford (1965), follows the Hallidayan linguistic model to consider language function as communication. As for translation, Catford distinguishes between textual equivalence and formal correspondence (Catford, 1965):

- Formal correspondent: the TL features that reside the same place in the SL

- Textual equivalent: the TL text that is the equivalent of a given SL text. 
In considering the concept of equivalence in Catford's view, the term "shift" comes to mind. He (1965) defines it as "departures from formal correspondence in the process of going from SL to TL, departures that can occur at linguistic level as graphology, phonology, grammar and lexis. Catford divides shift to two categories:

1. Level shift: expressing something using grammar in one language and lexis in another

2. Category shift that covers structural, class, unit, and intra-system shift.

\section{Functional Theories of Translation, Functional Era}

\section{Text types and text function themes}

Katharina Reiss draws on the notion of equivalence. To Reiss $(1977 / 89)$ observes that the text, not the word or sentence, is the level at which communication is realized. Her theory is related to language functions which correspond to language dimensions. Reiss gives the features of each text type as follows (Munday, 2001/2008):

1. Plain communication of facts. The language to communicate information is referential, with the content being the focus of communication.

2. Creative composition. The aesthetic dimension of language is paramount and the author is the main thing to attend.

3. Inducing behavioral responses. It is tried to persuade the reader to act in a certain way.

4. Audio-medial texts.

Reiss (1977/89) judges translation according to the degree of the transfer of the function of the ST into the target text. She prescribes certain translation methods based on text type (Reiss 1971):

1. The informative TT should convey, clearly, the content of ST.

2. The expressive TT is conveying the aesthetic form of ST.

Translation should identify and adopt the perspective of the ST.

Holz-Mänttäri builds on communication theory and action theory in order to develop a model for diverse translation situation. Action theory considers translation as purpose- oriented and accentuates on the message conveying function of translation (Munday, 2001/2008).

Holz-Mänttäri places translation in the sociocultural context and is attentive to the interplay between the translator and the institution. Schaffner (in Baker 1997) comments that the main purpose of translation action is for communication to take place across cultural barrier and that the source text is a device for the realization of communicative functions.

Hans J. Vermeer invented Skopos for the purpose of translation. Skopos theory concentrates on the goal of translation to decide the strategies to realizing the function of the TT. Thus, the purpose and function of translation are regarded as key issues (Munday, 2001/2008).

Reiss and Vermeer (1984) prescribe translation rules applicable to all texts. These rules include:

1. The key determining factor in a translation is Skopos.

2. TT offers information in TL concerning an offer of information in a SL.

3. TT does not offer information in a clearly reversible way.

4. TT must be internally coherent.
5. TT must be coherent with the ST.

6. The five rules above stand in hierarchical order, with the skopos rule predominating (Reiss and Vermeer, 1984).

Based on Skopos theory, the purpose of translation is a determining factor and we can translate the same text with different purposes in mind. Vermeer (1989/2004) maintains that the translator must consciously translate in accordance with some principle concerning the target text.

Christiane Nord in Text Analysis in Translation (1988/2005), is concerned with a functional model to examine text organization at sentence level. Accordingly, he distinguishes between documentary translation and instrumental translation:

1. Documentary translation serves as a document of a source culture communication between the author and the ST recipient (Nord, 2005).

2. Instrumental translation serves as message transmitting instrument in a new communicative action in the target culture.

Functional theories were the first to recognize changes or shifts in the translation studies. They, for example, moved the focus of attention away from the source text to target text and stressed cultural and linguistic features. Christiane Nord emphasized that the translator should make his mind concerning the proper translation method to meet recipients' needs and the nature of the text.

The following are three principles of functionalism that are to be attended in translation (Nord, 1997):

1. The significance of the translation commission

2. The importance of ST analysis

3. The functional hierarchy of translation problems.

\section{Discourse and register analysis approaches}

The Hallidayan Model of Language and Discourse

Halliday in his systemic functional grammar, focuses on the communication function of language and sees meaning as central, and relates it to the wider sociocultural context. Halliday gives special importance to register which is conditioned by the sociocultural environment. Register in turn consists of (Eggins, 2004):

1. Field: what is being written about

2. Tenor: who is communicating and to whom

3. Mode: the form of communication

Halliday analyzes the functions of language and ascribes three metafunctions language are to serve which include, the Ideational, the Interpersonal, and the Textual functions.

Julian House's Quality Assessment Model (1997) is concerned with the assessment of the quality of translation. In her model, she draws on Halliday's model of register analysis to systematically compare the textual quality of the ST and TT. The basis for this comparison is mainly register analysis which is realized by lexical, syntactic, and textual means.

In her approach, filed concerns the subject matter and social action covering the specificity of lexical items. Tenor refers to the addresser's geographical, social, and mental states. Mode relates to 'channel' (spoken/written, etc.) and the degree of participation between addresser and addressee (House, 1997). 
House (1997) makes reference to covert and overt translation. The former is the recreation, representation and reproduction of the function of ST. An overt translation is not original. In House's terms, an overt translation is one in which the addressees of the translation text are quite "overtly" not being directly addressed.

Mona Baker (1992) considers equivalence at different thematic, cohesion and pragmatic levels using a systemic approach and the integration of pragmatic level in which utterances are used in communicative situation.

To Baker, there are different aspects of pragmatic equivalence in translation. Pragmatics, to Baker, is the study of language use. Pragmatics is the contextual meaning as intended by participants in a specific situation (Baker, 1992). Based on her model, there are three major concepts of pragmatic: presupposition, coherence, and implicature.

Coherence concerns the receiver's expectations and experience of the world (Baker, 1992). It is defined by Baker as 'pragmatic inference'. Presupposition refers to the linguistic and extra- linguistic knowledge of the receiver. Baker is more careful about implicature: what is being implied rather than what directly said (Baker, 1992).

\section{Hatim and Mason: The Semiotic Level of Context and Discourse}

Hatim and Mason (1990 \& 1997) are other major translation theorists whose works developed out of the Hallidayan model of language. They give special importance to the ideational and interpersonal functions of language.

They combine bottom-up analysis and top-down consideration of the semiotic level of the text. Language and texts are means for the realization of sociocultural messages and power relations (Munday, 2001/2008). Based on their views (1997) discourse is a mode of thinking and writing involving social groups in conveying a particular attitude in areas of sociocultural actions.

Hatim and Mason (1997) strive to propose foundations for a model of analyzing texts. Their proposal is a list of elements to be considered in the analysis of translation. In particular, the concepts of dynamic and stable elements. Stable ST require a literal approach, while dynamic ST is more challenging and literal translation may not be appropriate.

\section{System theories}

Itamar Even-Zohar developed the polysystem theory. Working on literary works, Even-Zohar holds that a literary work is not produced and studied in isolation but constitutes part of a literary system. Thus, literature is an element of the social and cultural context and the key notion is that of the system, in which there is a dynamic interplay of 'mutation' and struggle for the primary position (Munday, 2001/2008).

Even-Zohar (1978) believes that the dynamic process is key feature in a polysystem. Accordingly, translation may hold a secondary or a primary position in the polysystem. To Even-Zohar, translated literature holds a primary position if it shapes the center of the polysystem.

In secondary position, translated literature is a marginal within the polysystem, holding a minor impact on the system. This secondary position, according to Even-Zohar $(1978 / 2004)$, is the typical case for translated literatures.

There are a number of advantages for the polysystem theory. Gentzler (2001), for example, lists some:

1. Literature is viewed in the light of social and cultural forces, and not in isolation.

2. Even-Zohar argues for the study of individual texts in the context of cultural and literary systems.

3. The stated definition of polysystem allows for variation based on the historical and cultural context.

\section{Toury and Descriptive Translation Studies}

In his Descriptive Translation Studies (1995) Toury is concerned with developing a descriptive system to replace the isolated translation studies. To Toury what is important is a systematic branch originated from clear assumptions and supported by methodology and research techniques, to develop translation methodology (Toury, 1995).

Toury attempts to develop a methodology for translation which is of utmost importance in the target culture. He (1995) offers a methodology for a description of the sociocultural system:

1. Situate the text within the target culture system, looking at its significance or acceptability.

2. Compare the ST and the TT for shifts, identifying relationships between 'coupled pairs' of ST and TT segments.

3. Attempt generalizations, reconstructing the process of translation for this ST-TT pair.

Toury in his case studies tries to identify translation trends, make generalizations and prescribe translation norms. To Toury (1995), norm is the transfering of general values or ideas shared by a community relevant to specific situations. He further classifies norms into different categories including: initial norm, preliminary norms, and operational norms.

Toury's identification of norms eventually leads to development of laws of translation. The laws of translation he considered are (1995):

1. The law of growing standardization: textual relations in source text are often modified.

2. The law of interference: interference from source text to target text is a kind of default. Interference is carryover of lexical and syntactical features into the TT, either negatively or positively.

Drawing on the concepts of norms, Andrew Chesterman (1997) proposes another set of norms:

1. Product or expectancy norms: expectations of readers of a translation concerning what a translation should be like.

2. Professional norms: comprising relation norm (relation between source text and target text), accountability norm (professional morality), and communication norm (communication between parties).

Lambert and Van Gorp are adopt a manipulation approach to literary translation. They draw on the works of Toury and Even-Zohar and propose a model to compare and describe the ST and TT literary systems and the relations within them. Each system involves a description of author, text and reader 
(Munday, 2001/2008). They (1985/2006) emphasize on the relationship between an individual translation and the overall context. Accordingly, what is important is not the study a single translated text or a single translator, but the study of association between this translation or this translator with other translations and translators.

To compare any act of translation and the literary system of source text and target text, they devise and describe schemes which consists of a description of text, author, and reader (1985/2006). Their scheme is divided into four parts:

1. Preliminary data: information on title page, metatexts (preface, etc.) and the general strategy (whether the translation is partial or complete).

2. Macro-level: the division of the text, titles and presentation of the chapters, the internal narrative structure and any overt authorial comment.

3. Micro-level: the identification of shifts on different linguistic levels.

4. Systemic context: here micro- and macro-levels, text and theory are compared and norms identified. Intertextual relations (relations with other texts including translations) and intersystemic relations (relations with other genres, codes) are also described (Munday, 2001/2008).

\section{CURRENT ISSUES IN TRANSLATION}

\section{Machine Translation}

The age of information and communication have changed the profession of translation and these changes are more prominent particularly in the types of electronic instruments used, the texts, and translator's ability. Machine translation (MT) is an emerging new technology which is inevitably altering translation. The speed, growing needs, time, and the amount of translation necessitate the use of automated machine translation (MT).

As Wagner (2003) states, developments in machine translation (MT) provide translators with assistance by using computers through translation stages. Computer software helps translators work faster with the translation task. Machine translation is inevitable these days as we glance at the vast amount of material to be translated. Thus, there is just too much in just too little time for a human translator to be able to handle without resorting to the "machine" for help.

According to Hutchins (2004), various reasons have led to the widespread use of machine translation. There is the ever-increasing need for it, and that the use of MT can increase the volume and speed of. Meanwhile, sometimes people want to reduce translation costs and top quality human translation is not always needed.

Although machine translation competes with the human translator, this technology cannot replace human translator, as there is always something left beyond reach for MT; that is, the human element of creativity. In fact, machine translation creates more work for human translators. Human translator fills the gap in conveying the dynamic cultural components of communication between nations as he is aware of nuances of meaning and subtle cultural elements unknown to the automated machine.
Machine translation can be used as a way of enhancing student involvement and attachment in the process of learning a foreign language. In the process of learning a foreign language, the learners can be pushed to further their language learning capacity by getting them to translate some extracts of the target language on their own or using machine translation as this task itself is fascinating as well as challenging. In this process, some useful expressions, quotations, verses, and proverbs can be used as prompts or stimulus and learners are asked to provide their equivalents in their mother tongues. This, in turn, helps expand learners' knowledge of the systems and structures of the target text and build more metalinguistic competence in the target language. The use of information technology and communication tools, like the Internet, is a great help in motivating students to translate and read more and familiarize themselves with the foreign language. Hashemi (2016) found that information and communication technology can serve the purpose of foreign language learning and foster a positive attitude towards learning.

\section{Translation and Culture}

As the facilities for contact and interaction between individuals and cultures increase, so does the need for translation. Translation acts as a mediator, or gap-filler, between languages, cultures and societies and it is through translation that we can ultimately be able to become acquainted with the world (Katan, 2004). Currently, translation studies have undergone vast development in scope to become a demanding field. Many factors have intensified this process, in particular the growing attention to the processes of socio-cultural communication that is made possible by means of translation.

The relationship between culture and translation has attracted attention; culture makes its way into human communication through translation. Translation is a mediator between cultures. According to Torop (2009), culture functions mainly through translational activity; culture can undergo innovation by the inclusion of new texts into it.

Translation is not only a linguistic process, but can also exert a profound political and social impact on cultural proximity and understanding. However, translation process can be considered as a way of propagandizing cultural as well as political disputes; politics and culture are paid special attention and regarded as important clues for translation. Ma (2010), for example, points out that feminist translation seeks to overthrow the submission of women to men.

Cultural turn is the first notion in cultural translation studies that was predicted by Poly-systems by Even-Zohar (1979) and Toury (1980). They believe that translation involves both language and culture. But, in cultural translation the focus is away from language towards the interaction between translation and culture, and the effects of culture on translation. To cut it short, the "cultural turn" states that neither the word, nor the text, but the culture is the operational unit of translation" (Lefevere \& Bassnett, 1990). Cultural Turn is taken by Cultural Studies to refer to the study of translation in terms of cultural, political, and ideological context. 


\section{Cultural manipulation}

Cultural manipulation is a special instance of cultural translation. Cultural manipulation is involved with the exploration of the symbolic relationship between language and culture in colonial conditions with an emphasis on the western translation as leading to the expansion of post-colonial ideology. Cultural manipulation deals with politics and ideology forming the postcolonial identity of a decolonized communities. Cultural manipulation involves: (a) the colonizer's generation of cultural knowledge about the colonized communities (b) how that Western cultural knowledge was applied to overcome a non-European people.

For some translation specialists in the field of cultural manipulation, the translation of texts can be seen as a particular case of sociopolitical act (Robinson, 1997), in which translation can lead to more serious political issues in producing and reading translations. For, translation is not separate from the milieu, rather it is a product of the context where the text functions. The critical stance adopted in this approach emphasizes on the political and cultural context where translation takes place.

Spivak (1993), a theorist of translation and cultural manipulation, in The Politics of Translation, is attentive to b o t $\mathrm{h}$ the political load of language, and specially the hegemonic position of English, and the need to translation as well. Spivak states that it is not translation which dictates its cultural meaning, rather the manner of translation. What matters is the attention given to the textual specificity of the works. Accordingly, cultural elements of the source language make their way into the target culture. This invasion is an invisible and subtle one which is by far less pronounced and evident in the surface. This hegemonic feature of the dominating language is the post-colonial aspect of culture and translation.

\section{Translation as a Language Teaching Technique}

The necessity of judicious use of translation in a language class, especially in elementary levels, is a matter with which nobody disagrees. Language teaching emerged out of translation and translation contributes to the development of language competence. It could be stated that lots of language learning has emerged out of translation. Alan Duff (1994) cites 5 reasons for using translation in the classroom:

1. Influence of the mother tongue: L1 definitely shapes our L2 learning and translation of L2 elements into L1 impacts on our understanding of the structures and patterns of it.

2. Naturalness of the activity: translation is a natural and essential activity

3. The skill aspect: translation increases our skills and knowledge of the L2 system

4. The reality of language: authentic translation material gets the learner in contact with the language as a whole

5. Usefulness

Translation as a language teaching technique enhances our understanding of the target language and makes its way to improve the quality of translated text. The value of any translation, mainly depends on the translator's cultural knowledge, skills, training, and expertise. Newmark (1995) considers some necessary features of a good translator:
- Reading comprehension ability in a foreign language

- Knowledge of the subject matter

- Sensitivity to both the source language and the target language

- Competence to write the target language dexterously, clearly and economically

Translation practitioners should be attentive to the significance of comprehension of a text as it impacts considerably on the quality of the translation. Thus the translator is supposed to be aware of reading strategies and discourse features to get the most of the reading test and convey the author's intentions to the reader.

As for translation procedures and strategies, translators must continuously opt for the most useful technique for the transfer of the ideas in the text. That is, tailoring the most appropriate technique to the requirements of the source text and not adopting a certain technique and using it all the time.

\section{Teaching Translation}

Any translation teaching or training program must be carefully designed so that the learners be able to benefit from it. It should be tried to avoid presenting translation as a boring activity, rather in the form of authentic material to help present cultural elements attractively. The desired translation teaching or training program should include the use of the following:

1. Linguistic, extra-linguistic and discourse Knowledge of the language

2. Cultural knowledge of the L2

3. Abundant use of reading comprehension techniques

4. Appropriate use of translation techniques

5. Knowledge of translation theories

Considering planning appropriate translation activities, it is important to incorporate real world translation activities and other skills. It is advisable to design group or individual activities with a communication gap where possible. It is worth mentioning that learner's opinion is of crucial significance. Thus, the learners should have clear ideas of the uses and the aims of the activities. In order to ensure optimum learner involvement, it is recommended that learners share in material development. It is also recommended to prevent overuse of mother tongue in group activities and, instead, focus on projects and hand-on activities which require learners to act dynamically and cooperatively in the class discussion on the content of the translation texts.

\section{Future Perspective}

It is hypothesized that the future is more involved with political and ideological considerations in the profession of translation. With the increased demand for the translation of cultural products as well as the multiplication of new intergroup beliefs, the realm of translation is to witness an intense attempt to propagate diverse truths and may lean in favor of powerful social forces trying to recruit new members.

It is to say that translation is not an innocent act, rather the theory of imperialism in practice controls everything by means of the propaganda of translation. In this process, the 
superior authority and the dominating knowledge and technology of the western European countries transform native identity and local cultures in the name of democracy, enlightenment, and globalization. Translation is western-oriented representing, above all, western dreams, fantasies, aspirations, and assumptions different from the native ones. Thus, translation in a way legitimizes and justifies western norms in the post-colonial situation. The disillusionment and despair inculcated in the natives as a result of inferiority towards the west make the way for the so-called obligation to 'civilize' them, albeit reluctant.

\section{Suggestions for Further Research}

The present authors were interested in exploring the colonial spread of English and the role played by translation in this concern, but due to time constraint they could not deal with it. It is suggested that it is an issue worth doing some research on. Also, we came to the idea of how native cultures try to make up for this deficiency in their "struggle for existence" and the search for replacing native elements in place of the overflowing flood of English elements.

\section{REFERENCES}

Baker, M. (1992). In Other Words: A Coursebook on Translation, London and New York: Routledge.

Baker, M. (1997). Non-cognitive constraints and interpreter strategies in political interviews, In K. Simms (ed.) Translating Sensitive Texts: Linguistic aspects, Amsterdam and Atlanta, GA: Rodopi.

Bassnett, S. (1980) Translation Studies. London, New York: Routledge.

Bassnett, S., \& Lefevere, A. (1990). Translation, History and Culture. London: Printer Publishers.

Bell, R. T. (1991) Translation and Translating: Theory and practice. London and New York: Longman.

Bijay, K. D., (2005). A Handbook of Translation Studies. (Atlantic Pu \& Dist., 2005), 104.

Catford, J.C. (1965). A linguistic theory of translation. Oxford University Press.

Chesterman, A. (1997) 'Ethics of translation', in M. Snell-Hornby, Z. Jettmarová and K. Kaindl (eds.). Translation as Intercultural Communication: Selected papers from the EST Congress, Prague 1995, Amsterdam and Philadelphia: John Benjamin's.

Dolet, E. (1540/1997). La manière de bien traduire d'une langue en aultre, Paris: J. de Marnef, trans. D. G. Ross as How to translate well from one language into another, In D. Robinson (ed.).

Dryden, J. (1680/1697/1992). Metaphrase, paraphrase and imitation. Extracts of 'Preface to Ovid's Epistles' (1680), and 'Dedication of the Aeneis' (1697), in R. Schulte and J. Biguenet (eds.) (1992). Theories of Translation, Chicago and London: University of Chicago Press.

Duff, A. (1994). Translation: Oxford University Press

Eggins, S. (2004). An Introduction to Systemic Functional Linguistics $\left(2^{\text {nd }}\right.$ edition). London: Continuum.
Even-Zohar, I. (1978). Papers in historical poetics, In B. Hrushovski and I. Even-Zohar (eds.) Papers on Poetics and Semiotics, Vol. 8, Tel Aviv: University Publishing Projects.

Even-Zohar, I. (2004). The position of translated literature within the literary Polysystem, in L. Venuti (ed.).

Firdaus, S. (2012). The Dialogue Volume. VII Number 3, Evolution of Translation Theories \& Practice.

Gentzler, E. (1993). Contemporary Translation Theories. London and New York: Routledge.

Gentzler, E. (2001). Contemporary Translation Theories. Clevedon: Multilingual Matters, $2^{\text {nd }}$ edition.

Harris, B. \& B. Sherwood (1978). Translating as an Innate Skill, In D. Gerver \& H. Wallace Sinaiko (eds.). Language, Interpretation and Communication, New York \& London: Plenum.

Hashemi, Ali (2016). The Impact of Information and Communication Technology (ICT) on Teaching English to College Students. EFL Journal Vol. 1 No. 3, 2016

Hatim, B. and Mason, I. (1990). Discourse and the Translator. London and New York: Longman.

Hatim, B. and Mason, I. (1997). The Translator as Communicator. London and New York: Routledge.

House, J. (1977). A Model for Translation Quality Assessment. Tübingen: Gunter Narr.

Hutchins, J. (2004) "Machine Translation and Computer-Based Translation Tools: What's Available and How It's Used." A New Spectrum of Translation Studies. Ed. José Maria Bravo. University of Valladolid, Valladolid, Spain.

Jakobson, R. (1959). On linguistic aspects of translation. In L. Venuti (Ed.), The translation studies reader ( $\left.2^{\text {nd }} \mathrm{ed}.\right)$. London and New York: Routledge.

Katan, David (2004). Translation Theory and Professional Practice: A Global Survey of the Great Divide. Hermes - Journal of Language and Communication Studies no 42-2009

Koller, W. (1979). Einführung in die Übersetzungswissenschaft, Heidelberg- Wiesbaden: Quelle und Meyer.

Koller, W. (1979/1989) Equivalence in translation theory, translated by A. Chesterman, in A. Chesterman (ed.).

Koller, W (1995). The Concept of Equivalence and the Object of Translation Studies. Target 7, 191-222.

Lambert J.-R. and H. van Gorp (1985). 'On describing translations', in T. Hermans (ed.) (1985a), pp. 42-53 reprinted in D. Delabastita, L. D'hulst and R. Meylaerts (eds) (2006) Functional Approaches to Culture and Translation: Selected Papers by José Lambert, Amsterdam and Philadelphia: John Benjamin's.

Lörscher, W. (1991). Translation performance, Translation process, Translation strategies: A Psycholinguistic Investigation. Tubingen: Narr.

Ma, H. J. (2010). Selected Readings of Contemporary Western Translation Theories. Beijing: Foreign Language Teaching and Research Press.

Munday, J. (2001). Introducing translation studies: Theories and application. London and New York: Routledge.

Newmark, P. (1981). Approaches to Translation. Pergamon: Oxford and New York.

Newmark, P. (1998). More Paragraphs on Translation. Clevedon: Multilingual Matters. 
Nida, E. A. and C. R. Taber (1969). The Theory and Practice of Translation, Leiden: E. J. Brill

Nida, E. A. (1964). Toward a Science of Translating: With Special Reference to Principles and Procedures Involved in Bible Translating, Leiden: E.J. Brill.

Nord, C. (1988). Textanalyse und Übersetzen: Theoretische Grundlagen, Methode und didaktische Anwendung einer übersetzungsrelevanten Textanalyse, Heidelberg: J. Groos; translated (2005, $2^{\text {nd }}$ edition) as Text Analysis in Translation: Theory, Methodology and Didactic Application of a Model for Translation-Oriented Text Analysis. Amsterdam: Rodopi.

Nord, C. (1997). Translating as a Purposeful Activity: Functionalist approaches explained. Manchester: St Jerome.

Qabil, K. (2005). Translation Studies: A Montage of Literary Essays and Critical Articles op.cit.

Reiss, K. (1971/2000). Möglichkeiten und Grenzen der Übersetzungskritik, Munich: M. Hueber, translated (2000) by E. F. Rhodes as Translation Criticism: Potential and Limitations, Manchester: St Jerome and American Bible Society.

Reiss, k. (1977/89). 'Text types, translation types and translation assessment', translated by A.

Chesterman, in A. Chesterman (ed.) (1989).

Reiss, K. and H. J. Vermeer (1984). Grundlegung einer allgemeinen Translation theorie, Tübingen: Niemeyer.

Richards, I.A. (1953). "Toward a Theory of Translating", Studies in Chinese Thought, ed. Br Arthur F. Wright, Chicago, University of Chicago Press.

Robinson, D. (1997). Translation and the repayment of debt. Delos 7,1-2.

Schleiermacher, F. (1813/1992). On the different methods of translating. In Rainer Schulte and John Biguenet (eds.). Theories of Translation. Chicago: University of Chicago Press.
Shuttleworth, M. \& Cowie M. (1997). Dictionary of Translation Studies. Manchester: St. Jerome Publishing.

Snell-Hornby, M (1988, revised 1995). Translation Studies: An Integrated Approach. Amsterdam and Philadelphia, PA: John Benjamin's.

Spivak, G., (1993). The Politics of Translation: Outside in the Teaching Machine. New York and London: Routledge.

Steiner, E. (1998). A register-based translation evaluation: an advertisement as a case in point. Target, 10(2). 291-318

Toury, G. (1995). Descriptive Translation Studies - And Beyond. Amsterdam and Philadelphia, PA: John Benjamin's.

Toury, G. (1980). In search of a theory of translation. Tel Aviv. Porter Institute for Poetics and Semiotics

Tynjanov, J. N. (1927). Arkhaisty i novatory, Moscow: Akademia, translated (1971) by C. Luplow as On literary evolution, In L. Matejka and K. Pomorska (eds).

Venti, L. (1995/2008). The Translator's Invisibility: A History of Translation. London and New York: Routledge.

Vermeer, H. J. (1989/2004). Skopos and commission in translational action. trans. A. Chesterman, in A. Chesterman (ed.), Readings in Translation Theory, Helsinki: OyFinn Lectura Ab, pp. 173-87, reprinted in L. Venuti (ed.) The Translation Studies Reader (2 ${ }^{\text {nd }}$ edition), London and New York: Routledge.

Vinay, J.-P. and J. Darbelnet (1958, $2^{\text {nd }}$ edition 1977) Stylistique comparée du français et de l'anglais: méthode de traduction, Paris: Didier, translated and edited by J. C. Sager and M.-J. Hamel (1995) as Comparative Stylistics of French and English: A Method-ology for Translation, Amsterdam and Philadelphia, PA: John Benjamin's.

Wagner, E. (2003). Why International Organizations Need Translation Theory. In L. P. González (Ed.). Speaking in Tongues: Language across Contexts and Users. Valencia, Spain: Universidad de Valencia. 